\title{
Investigation of Hydrological Behaviour of In Situ Bauxite Residue for Closure and Rehabilitation Design
}

\author{
N. Amoah Worsley Alumina Pty Ltd, Australia \\ J. Phillips GHD Pty Ltd, Australia \\ S. Vlahos Worsley Alumina Pty Ltd, Australia
}

\section{INTRODUCTION}

Over 20 million $\mathrm{m}^{3}$ of residue from the alumina refining industry are produced in Western Australia each year. The residue is normally stored in engineered earth impoundments termed as Tailings Storage Facilities (TSFs). In recent years the closure and rehabilitation of such TSFs have become a very important aspect of overall strategic plans of many mining operations.

The slurry deposition method of tailings disposal results in considerable volumes of water being deposited with tailings, some of which is still retained within the tailings deposit even after closure. It is important to know the future behaviour of this water, particularly if it is contaminated. Water can influence the closure of a tailings system in several ways including the following:

- Waterlogging of the surface.

- Capillary rise of contaminated water.

- Major settlements of the tailings surface if the water table within the residue falls.

- Underseepage which may infiltrate groundwater or need interception/treatment.

- Rainfall infiltration may dissolve contained salts.

At Worsley Alumina Refinery, the first Bauxite Residue Disposal Area (BRDA 1) was constructed in 1984. Residue deposition continued with the various stages of embankment raising. BRDA 1 reached the final design height in 1995. The total footprint covers 75 ha. The upper surface covers 50 ha, has a maximum depth of residue of about $45 \mathrm{~m}$ and contains caustic residue and approved refinery wastes.

The hydrological behaviour of the tailings in BRDA 1 has undergone intense study in recent years. One of the primary aims has been to develop a conceptual model that could be used to predict the rate and quantity of liquor movement through the residue into the underdrainage system and to allow the estimation of potential liquor quantities to be treated after closure of the refinery. As part of closure design, adequate knowledge of this was required for the evaluation and design of a capping system for the BRDA.

Investigations consisted of detailed instrumentation, several years of in situ monitoring, drilling, in situ testing and laboratory tests to characterise both the geotechnical and hydrological behaviour of the bauxite residue. The importance of rainfall penetration and its relationship with a perched and long-term watertable was examined.

A predictive model was developed using the interrelationship between these factors to determine the impact on closure and rehabilitation design. 


\section{FIELD INVESTIGATIONS}

During winter months, a pond forms on the residue surface and gradually drains via decant towers and seepage through residue. In order to determine whether the ponds are an expression of the water table within the residue during winter months, it was decided to carry out field investigations. The depth to water table, moisture profile within the residue and the nature and vertical extent of the crack system is crucial to understanding the water movement. An initial field investigation involving 5 test pit excavations (Figure 1) was conducted to investigate these characteristics in the upper $5 \mathrm{~m}$ of residue.

There was no uniform relationship between the moisture content and depth (Figure 2). Moisture content seemed to change according to the layering cycles associated with red mud deposition. No free water was observed.

An interesting observation in many pits was the pattern of cracks. The cracks extended from the surface to the entire depth of the excavation with signs of cracks continuing with depth. There was no consistent relationship between crack width and depth of excavation. The widths changed randomly with depth, some cracks were open while others were filled with fines. Most of the cracks were sub vertical but with a few horizontal ones and crack interconnections in all directions.

\section{$3 \quad$ HYDRAULIC TESTING IN THE CRACKED RESIDUE}

A basin infiltration test was conducted to simulate the hydraulic recharge through the cracked residue surface during winter months. The test was conducted by excavating a $4 \mathrm{~m}$ deep test pit (Figure 3) located $1.5 \mathrm{~m}$ away from nearby clustered piezometers set at 5,10 and $20 \mathrm{~m}$ below the surface. The water levels in the piezometers were recorded and then the pit was filled with water over a period of about $1 / 2$ hour.

At about $1 / 2 \mathrm{hr}$ after filling the pit, the water level in the deepest piezometer started to rise while the others remained unchanged. Over the initial period of 3 hours the deep and intermediate piezometers showed significant rises in head but there was virtually no change in the shallow piezometer. The monitoring of the water levels in the pit and in the piezometers continued for over three weeks.

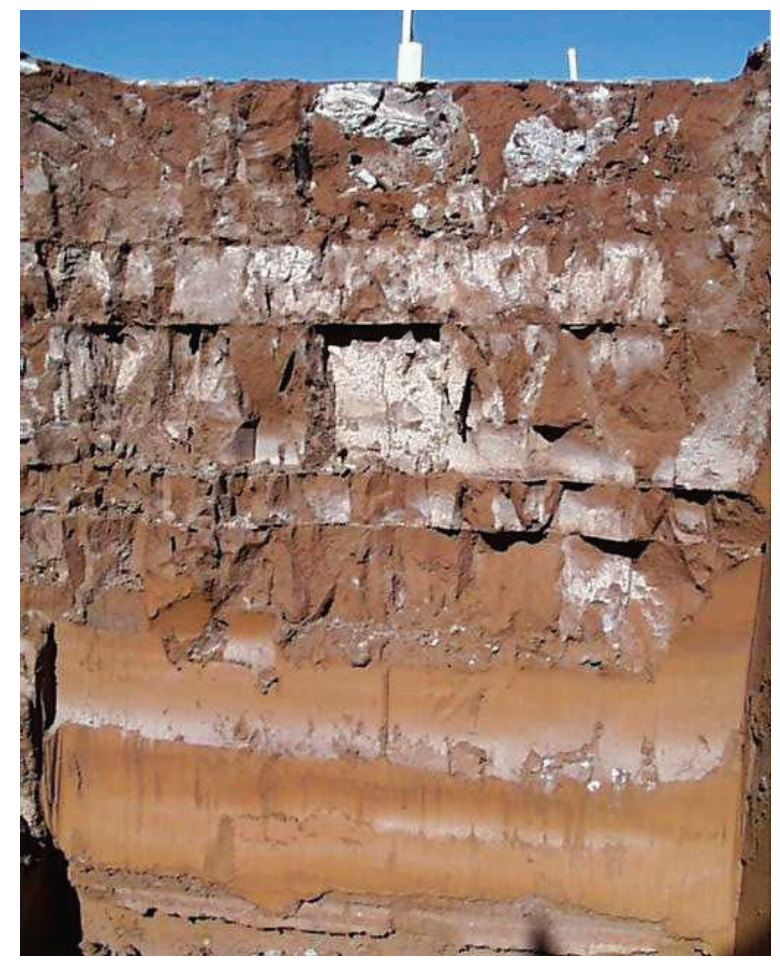

Figure $1 \quad$ BRDA1 Test Pit B1T5 


\section{Gravimetric Moisture Content (\%)}

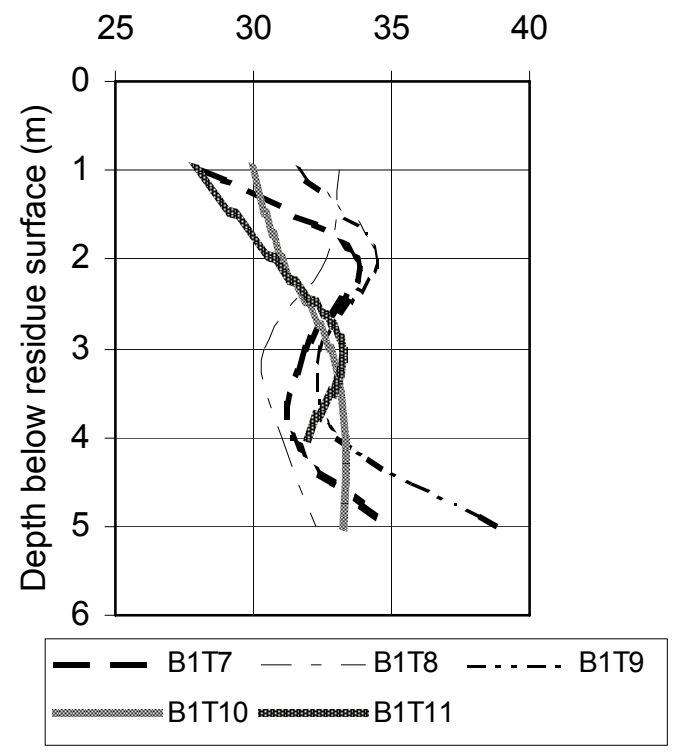

Figure 2 Moisture profile for test pits

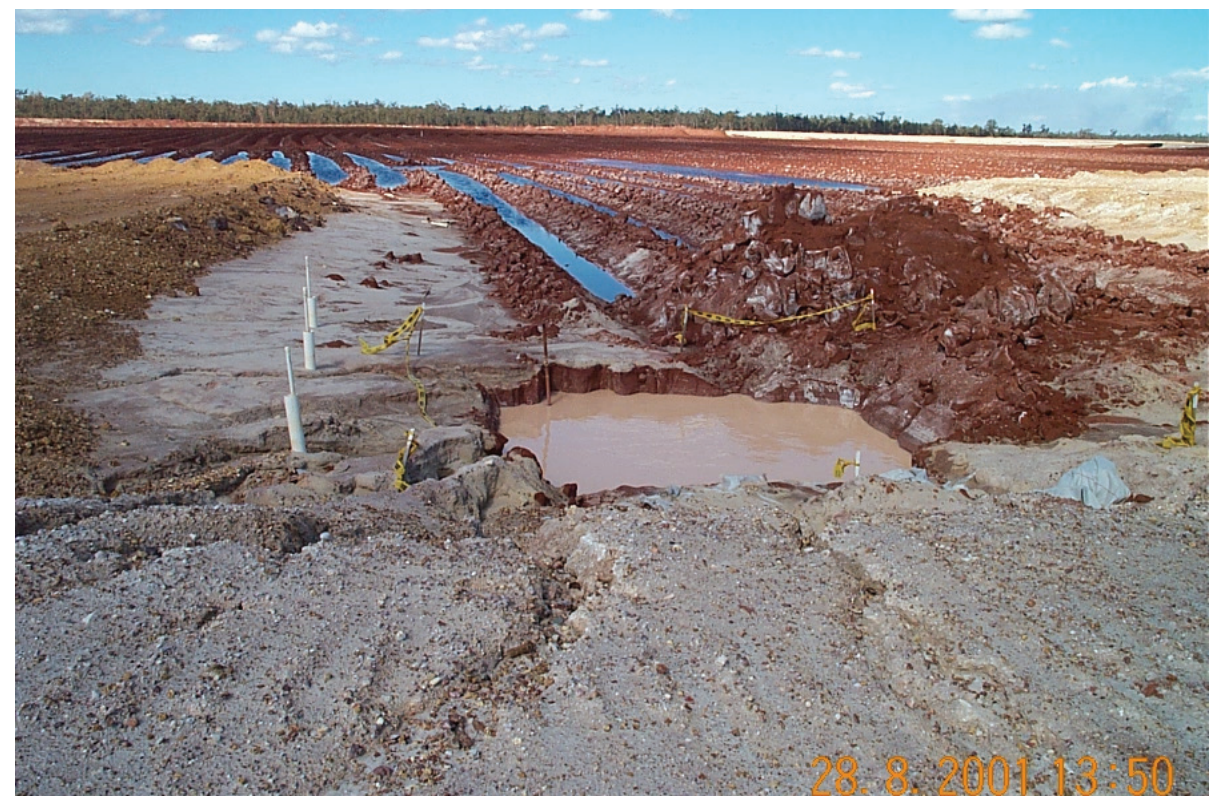

Figure $3 \quad$ Field infiltration test

Water levels in the shallow piezometer started to rise three days after filling the pit. There were reductions in levels in all piezometers after their initial rise. Water levels in the pit dropped very slowly for the first week and virtually became stagnant.

The water level in the pit was expected to drop at a significant rate as water moved through the crack system into the surrounding areas, however this did not happen. The quick response of the deep piezometer, followed by the intermediate piezometer and the shallow piezometer indicates the complexities involved in the hydrologic behaviour of in situ tailings. (The theory postulated to explain this phenomenon was that water flowed to the bottom of the crack system first and then gradually filled up the crack voids in the vicinity. It may then be that some of the finer crack connections closed due to residue swelling, preventing 
further flow from the pit whilst allowing dissipation of the first flow of water either laterally or vertically to greater depth.) However, it was observed that cracks at the edge of the pit remained open even where visible underwater. The fact that water level in the pit did not continue to fall may indicate that the cracks are not pervasively connected over large areas at depth.

Although the results of this experiment were not conclusive, the initial rise in water levels in the piezometers reflects similar behaviour during the early periods in winter. The stagnation of water flow from the pit may also reflect the winter ponding on the residue surface and generally suggest a lower infiltration rate through the residue than might be estimated from observation of the crack pattern.

\section{GENERAL BEHAVIOUR OF WATER LEVELS}

A review of piezometric data gathered over several years led to the following summary:

- In general, water levels fluctuate according to winter recharge and summer recession with many shallow piezometers becoming dry in summer.

- All the shallow piezometers show erratic water level changes between the seasons. These piezometers are in the cracked zone and it is observed that the cracks rapidly fill with rainfall runoff, applying a rapid increase in pressure in this zone. Evaporation loss in summer draws on the free water in the cracks, rapidly lowering water levels in the cracks.

- Water level data for the shallow piezometers and many intermediate piezometers may not fully indicate the hydraulic behaviour at the upper layers of the residue. Such piezometers will not give reliable conclusions on temporal and spatial distribution of hydraulic heads in the residue.

- The temporal and spatial variations in groundwater movement in the residue can only be analysed by using data from piezometers that are over $10 \mathrm{~m}$ deep.

- Intermediate and deep piezometers show consistent trends regardless of winter ponding or summer drying. This suggests that a low permeability layer occurs somewhere below the (cracked) upper layers, therefore controlling flow into the lower layers.

- Hydrographs of the clustered piezometers indicate a downward hydraulic gradient (Figure 4), indicating that the drainage layer beneath the residue is maintaining low pressure at the base. This indicates that the downward drainage of liquor will allow the progressive drop of water table.

- Analyses of the hydrographs for the deep piezometers and some intermediate piezometers indicated a consistent downward trend of about $0.7 \mathrm{~m}$ per year in annual static water levels (Figure 5).

- In summer, an average fall in water table is between $1.2 \mathrm{~m}$ and $2.4 \mathrm{~m}$.

- Some piezometers showed an upward rise in static water levels for the winter period. The rate of upward rise was between $0.24 \mathrm{~m}$ and $0.36 \mathrm{~m}$ per year. The same piezometers also showed a downward drop in the summer months at a rate between $0.48 \mathrm{~m}$ and $0.96 \mathrm{~m}$ per year. 


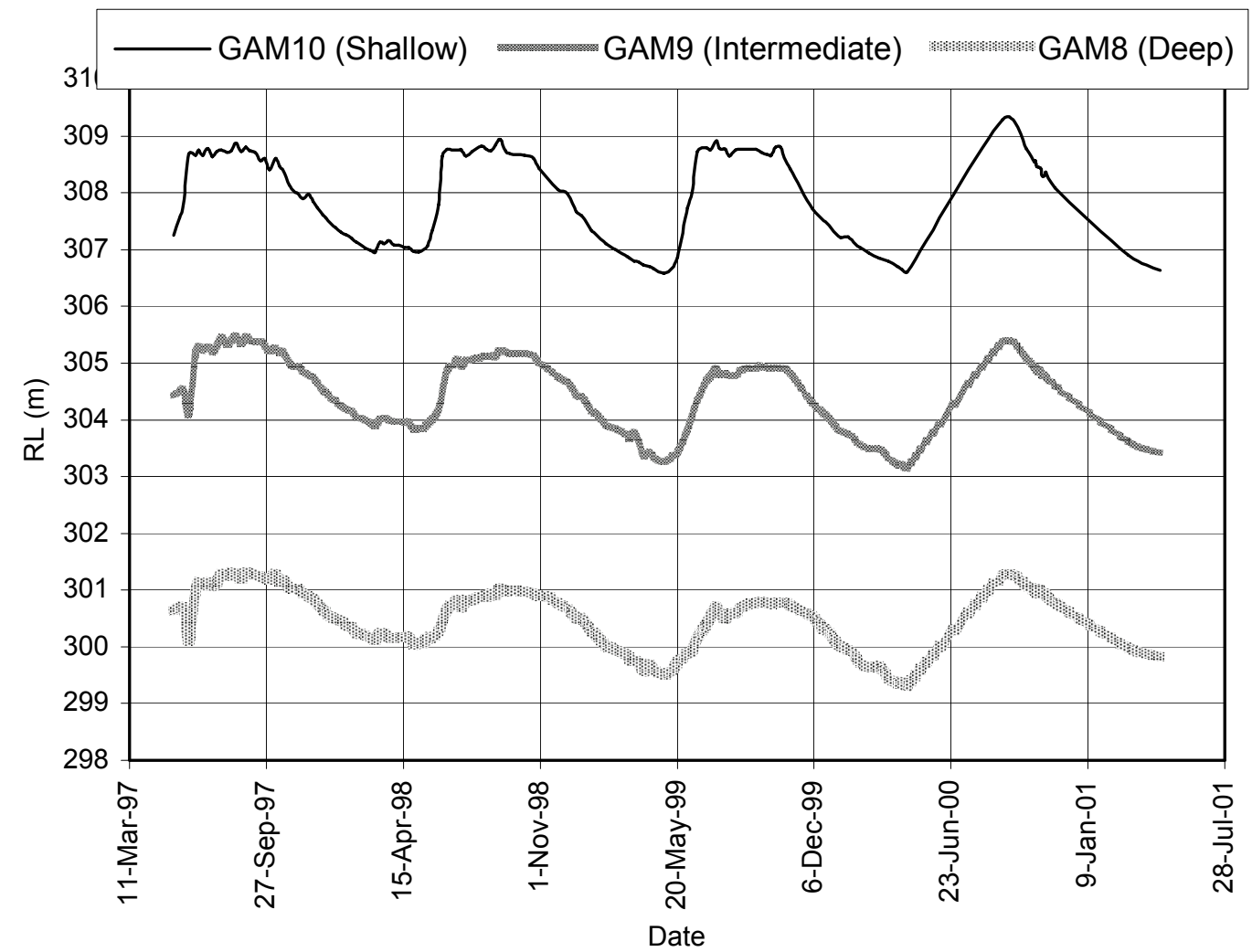

Figure 4 Hydrographs of piezometer cluster

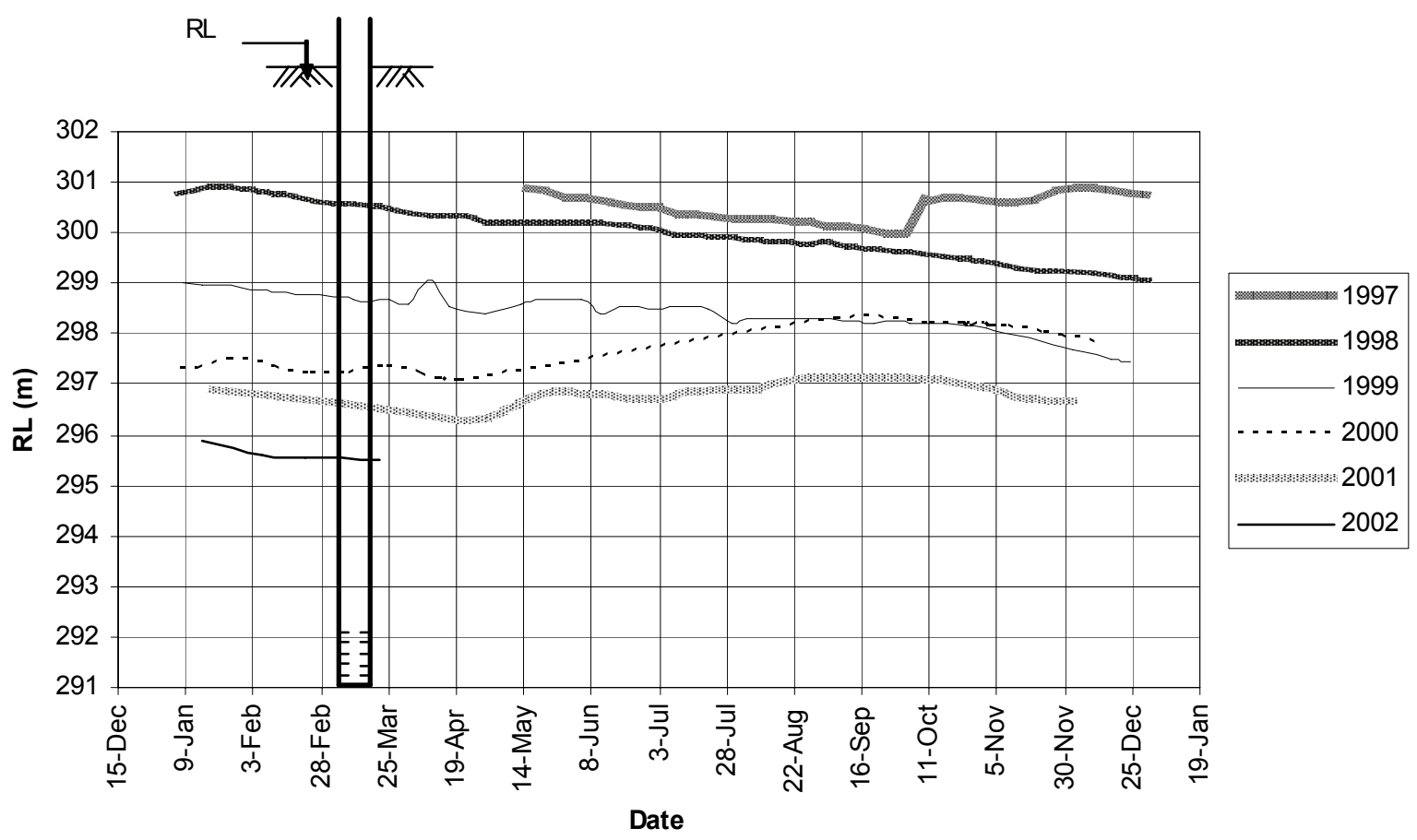

Figure $5 \quad$ Piezometer levels over 5 years 


\section{FURTHER SITE INVESTIGATIONS}

Three $150 \mathrm{~mm}$ boreholes were drilled using hollow flight augers and a piston sampler to determine the location of a water table within the residue, the extent of cracking at depth, strength/density, consolidation of the residue with depth and their effect on the hydraulic conductivity.

Core samples confirmed the pervasive nature of the cracks to about $10 \mathrm{~m}$ depth. Between $10 \mathrm{~m}$ and up to about $16 \mathrm{~m}$ depth, cracks were periodically observed but were not as frequent nor as wide as in the upper layers. The various layers corresponding to residue deposition and drying cycles were identified by a horizontal thin white crust. Throughout the drilling period there was no evidence of influx of free water from cracks into any of the boreholes.

The moisture content and consistency did not reveal any uniform relationship with depth but seemed to follow the deposition cycles. Samples ranged from firm to stiff with moisture contents varying from slightly moist to very moist.

After the static water levels had stabilised in the holes, hydraulic conductivities were determined by adding a slug of water, and then measuring water levels as they dropped back to the static level. Calculated hydraulic conductivities were:

- $1.2 \times 10^{-8} \mathrm{~m} / \mathrm{sec}$ (approximately $17 \mathrm{~m}$ deep).

- $5.2 \times 10^{-9} \mathrm{~m} / \mathrm{sec}$ (approximately $20 \mathrm{~m}$ deep).

- $2.6 \times 10^{-9} \mathrm{~m} / \mathrm{sec}$ (approximately $27 \mathrm{~m}$ deep).

As part of Worsley's data collection system, flow measurements have been taken since 1998 at the various underdrain pipes that collect downwards seepage through the residue. Underflow measurements at BRDA 4 were analysed to estimate hydraulic conductivities. The equivalent hydraulic conductivities of the residue overlying the blanket were estimated to be between $1.1 \times 10^{-8} \mathrm{~m} / \mathrm{s}$ and $1.4 \times 10^{-8} \mathrm{~m} / \mathrm{s}$.

The in situ dry densities ranged from 1.51 to $1.78 \mathrm{t} / \mathrm{m}^{3}$, varying randomly with no unique relationship with depth. Similarly, no unique relationship existed between the moisture contents and depth. The density and moisture profiles seem to be controlled by the deposition and drying cycles. Most of the dense layers coincide with the upper layers of each deposition cycle.

The results suggest that although overburden pressure will cause consolidation, layers that have experienced sun drying will have higher densities and lower moisture contents than can be produced by consolidation. The high suction pressures during summer drying produce a more significant change in density and void ratio than that produced by overburden pressure.

Cone Penetrometer Testing was used to measure strength profiles and pore pressure. Negative pore pressures up to $-55 \mathrm{KPa}$ were measured at $2 \mathrm{~m}$ depth but reduced gradually with depth. At about $8 \mathrm{~m}$ depth the pore pressure values approached zero and at $11 \mathrm{~m}$ depth positive pressures between $4 \mathrm{KPa}$ and $7 \mathrm{KPa}$ were measured in all three test locations. These findings suggest that the true water table (the point where the pressure is equal to zero) at the time was around $9 \mathrm{~m}$ to $10 \mathrm{~m}$ deep. 
In order to observe groundwater behaviour in the upper layers, a pit approximately $4.5 \mathrm{~m}$ wide $\mathrm{x} 5 \mathrm{~m}$ long and $3 \mathrm{~m}$ deep was excavated approximately $400 \mathrm{~m}$ away from the previous pit discussed earlier. Two sets of clustered piezometers were installed about $4 \mathrm{~m}$ away from the pit, at depths below residue surface of $3.5 \mathrm{~m}$, $6 \mathrm{~m}, 12 \mathrm{~m}$ and $17 \mathrm{~m}$. Figure 6 shows the water levels in the various piezometers at different dates.

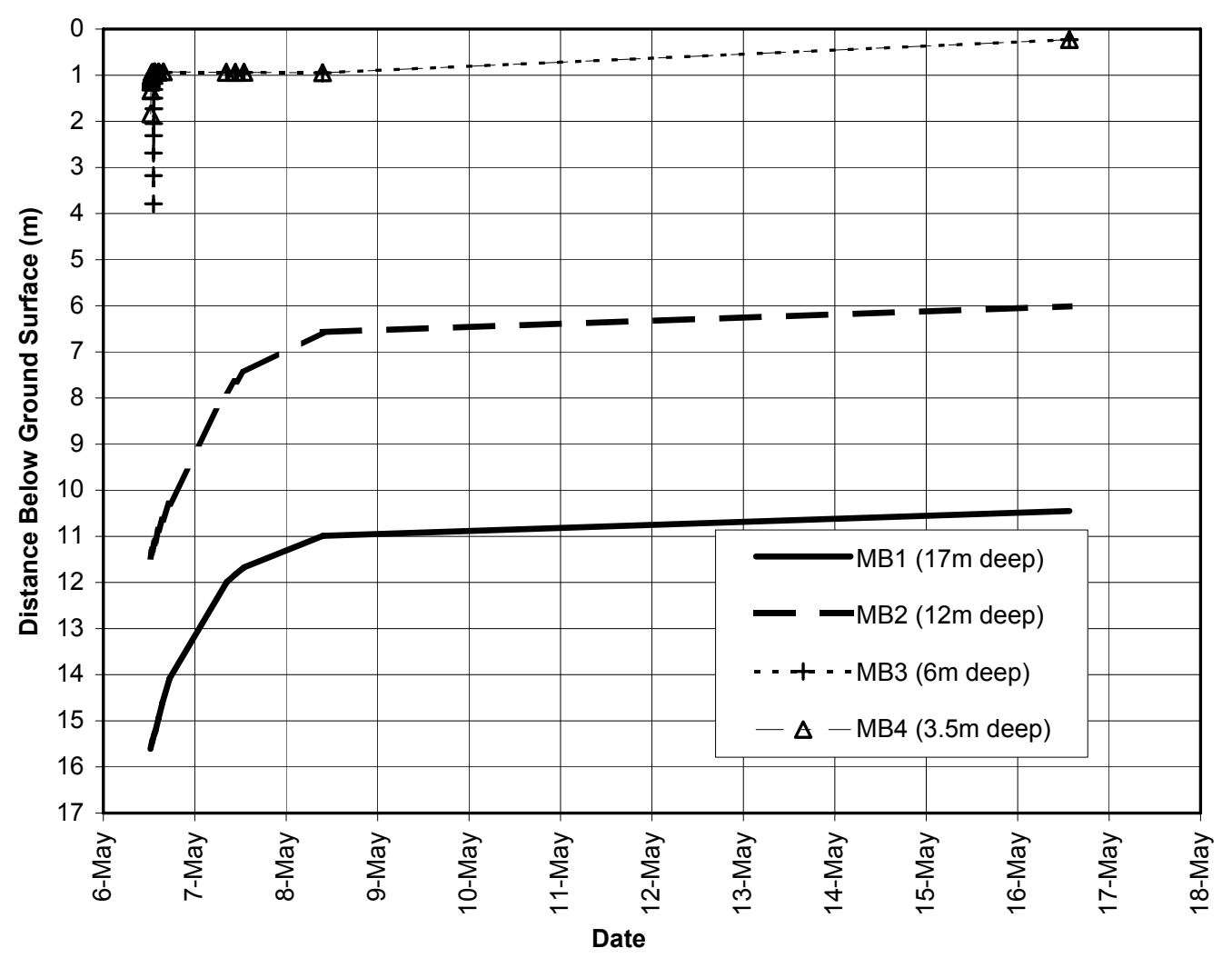

Figure $6 \quad$ Water levels after filling of pit 
Observations confirmed that water levels measured in different piezometers are influenced by different systems. A low permeability layer appears to occur around $9 \mathrm{~m}$ and $10 \mathrm{~m}$ depth from the residue surface, forming an aquitard. The water levels in piezometers located in the upper $6 \mathrm{~m}$ within the residue are therefore influenced by a separate perched water system while those piezometers below $10 \mathrm{~m}$ deep are located in the main residue water system. Other minor aquitards may exist but this cannot be confirmed.

The downward gradient confirms that in general the groundwater in the residue flows towards the underdrainage systems (gravel and pipe network) at the base of the residue.

\section{GROUNDWATER BEHAVIOUR WITHIN THE RESIDUE}

The exposed surface of the residue is subjected to infiltration in winter and evaporation in the summer. Infiltration from the surface rainfall causes a downward vertical flow through the residue into the water table. This eventually causes the water table to rise and may even rise above the surface to form a pond if there is sufficient rainfall. However, a pond can equally form if the rate of rainfall exceeds the rate of infiltration, forming a perched water table above the true water table.

Drying during summer causes air to enter the voids in the residue. The capillary forces associated with these microscopic bubbles create negative pressures which pull the soil particles together into a more dense state and pulls water up from lower levels (soil suction). With long summer evaporations the water table drops and suction pressures become more negative. The high suction pressures cause the residue to shrink (become more dense) and the hydraulic conductivity reduces except where cracks occur.

From a hydrogeological point of view, water will flow in the direction of the pressure gradient, i.e. upward towards negative pressures near the surface (capillary flow). This leads to the capillary fringe close to the residue surface. If a capping system with an infiltration barrier having hydraulic conductivity of $1 \times 10^{-8} \mathrm{~m} / \mathrm{s}$ or more is selected then it is important to characterise the flow through the thick capillary fringe in order to quantify the potential infiltration.

In interpreting the site investigation, the residue mass was simulated as four theoretical layers:

- The upper zone, representing the zone within $8 \mathrm{~m}$ from the residue surface with bulk hydraulic conductivity (allowing for cracks) $2.6 \times 10^{-6} \mathrm{~m} / \mathrm{s}$.

- The intermediate zone representing the zone between $8 \mathrm{~m}$ and $14 \mathrm{~m}$ below the residue surface with hydraulic conductivities of $1.2 \times 10^{-8} \mathrm{~m} / \mathrm{s}$.

- The deep zone representing the zone between $14 \mathrm{~m}$ and $20 \mathrm{~m}$ below the residue surface with hydraulic conductivities of $5.2 \times 10^{-9} \mathrm{~m} / \mathrm{s}$.

- The very deep zone representing the zone beyond $20 \mathrm{~m}$ from the residue surface with very low hydraulic conductivities less than $2.6 \times 10^{-9} \mathrm{~m} / \mathrm{s}$.

In general most of the upper $8 \mathrm{~m}$ of residue has a high hydraulic conductivity mainly due to the dense network of cracks. Flow through the upper zone can be conceptualised as flow through a dual porosity medium with a primary porosity of the residue, but a secondary porosity due to the cracks. The cracks are potentially highly interconnected and the total porosity is dominated by secondary porosity from the cracks.

As the number of cracks reduce with depth, the fracture interconnectivity probably also reduces. The total porosity of the residue mass is then mainly dominated by the primary porosity and to a lesser extent by the few cracks that may still occur. The high suction pressures cause consolidation of the residue and together with the reductions in crack network lead to low permeability towards the base of the upper zone.

It is likely that this depth around $9 \mathrm{~m}$ and $10 \mathrm{~m}$ becomes an infiltration barrier with reduced hydraulic conductivity compared to the highly cracked zone above it. Vertical flow of water is therefore limited by this barrier. In winter, the abundant supply of water exceeds the infiltration capacity of the barrier, all the cracks become filled with water and ponds form on the residue surface. These ponds mainly disappear due to evaporation during the summer, indicating that the ponds do not represent the true water table in the residue.

The residue as a whole is therefore considered as an anisotropic and non-heterogenous mass with layers of various permeabilities reflecting the filling cycles. The rate at which surface water recharges into the lower 
layers and into the under drains is ultimately influenced by the low permeabilities of the layers at depth in the profile.

\section{MATHEMATICAL MODEL FOR HYDROGEOLOGICAL BEHAVIOUR}

A mathematical model was developed to simulate and quantify the relationship between the various parameters affecting the hydrogeological behaviour of the residue. Once validated, the model was used to assess future changes including the effect of various cover systems.

The system was initially modelled in one-dimensional form for a steady state case. Hydraulic conductivity of a soil column was initially assumed to be a single value under homogeneous conditions. The model was then developed by obtaining an analytical solution of the one-dimensional steady state equation (Laplace equation) for groundwater flow in the vertical direction. The model was then divided into layers and different hydraulic conductivities were assigned to each layer to model the effects of heterogeneity and anisotropy due to residue layering.

The water pressure head distribution was found to be non-linear under steady state conditions, being a function of hydraulic conductivities assigned to the layers. Temporal reductions in the water table were accompanied by temporal reductions in the piezometric levels located at any depth below the water table.

The simulations assumed an average $30 \mathrm{~m}$ depth residue, divided into four layers of different hydraulic conductivities based on field tests. Results were compared with groundwater level data obtained since 1977 to match the rate of drop in water levels in the piezometers during both summer and winter.

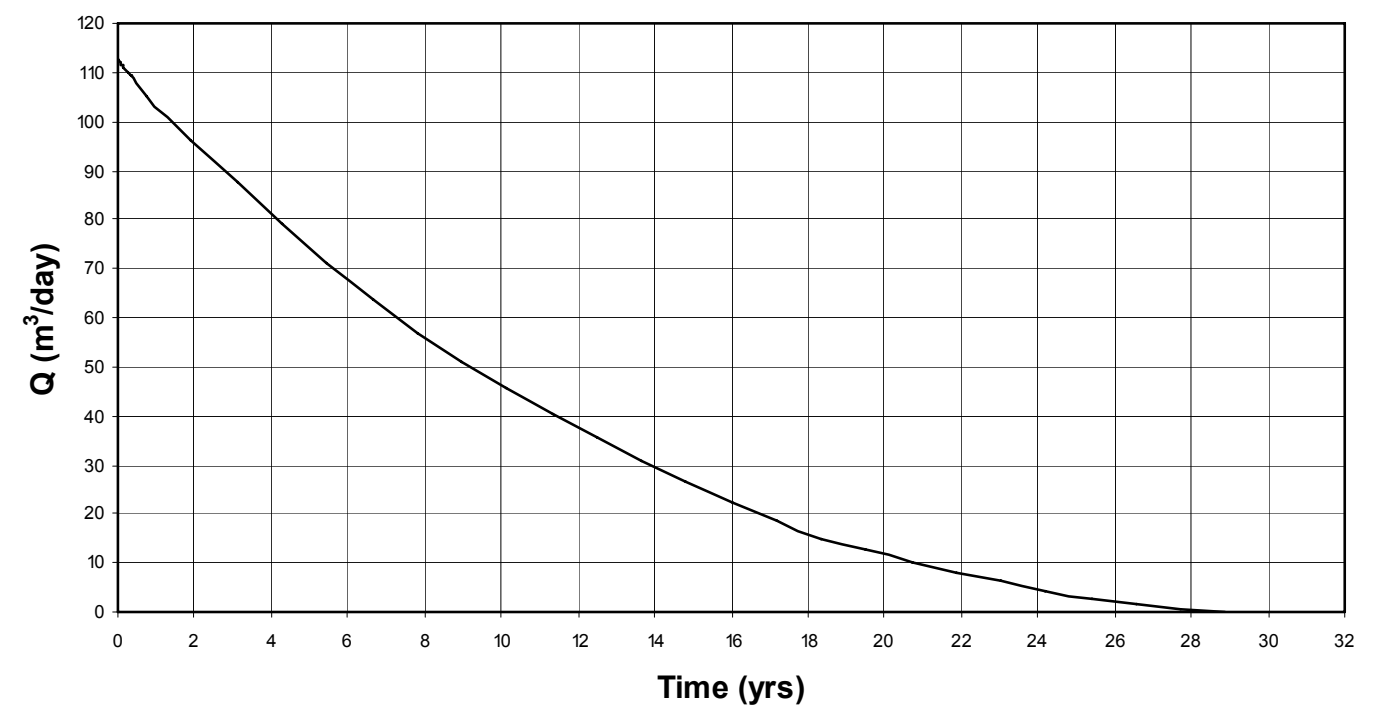

Figure $7 \quad$ Water table and underflow quantities 
Following calibration against field results, the model was used to predict the time the water table would take to drop to the base of the residue. It was also possible to estimate the length of time that liquor has to be collected from the under drains for treatment.

Numerical simulations suggest that the water table will fall from an initial level of about $8.0 \mathrm{~m}$ depth to about $30 \mathrm{~m}$ depth over a period of between 19 to 30 years. The 19 years represents the optimistic case of no infiltration and 30 years represents the practical case based on continuing the current behaviour. The underflow quantities obtained from model simulation for the practical case is shown in Figure 7.

\section{REQUIREMENTS FOR COVERS}

The results of the investigation indicated the following points:

- The residue material does not undergo significant shrink/swell, therefore the existing cracks that form in deposited residue are unlikely to close when wetted.

- The residue at BRDA 1 has consolidated to high density and strength due partly to overburden pressure but mostly due to the drying of the various layers during the deposition cycles. It is expected that any capping system will suffer only moderate settlement.

- The true water table is below the residue surface even in winter months. The ponds that form on the residue surface reflect perched water tables due to layers of low hydraulic conductivities at depths where the crack network is minimal.

- The water table within the residue is dropping year by year in spite of winter recharge.

- An estimated hydraulic conductivity between $2.6 \times 10^{-9} \mathrm{~m} / \mathrm{s}$ and $1 \times 10^{-8} \mathrm{~m} / \mathrm{s}$ controls the rate and quantity of liquor that enters the under drains.

- A capping system with the aim of reducing recharge sufficiently to ensure the continual reduction of the water table should have a hydraulic conductivity not greater than $2 \times 10^{-9} \mathrm{~m} / \mathrm{s}$.

- It is estimated that if a low permeability cap is used, it will potentially take between 19 years and 30 years to reduce the water table and hence underdrainage to nearly zero.

The hydrogeological investigations revealed several issues that will potentially affect the capping systems to be chosen:

- The cap should minimise infiltration of surface water into the waste so that the quantity of liquor and the length of time it is collected for treatment are minimised.

- The cap should minimise the capillary rise of liquor into the capping system thus limiting salt rise.

- The capping system should support sustainable vegetation growth.

- The capping system should have a long-term performance.

By using these fundamental requirements, the conceptual covers should have distinct layers which perform specific functions to achieve the above goals.

The infiltration barrier is the main separating layer between the residue and the environment. The lower the permeability of the material used for construction of this layer, the more effective it is as a barrier to infiltration. Conventionally this layer may be constructed of low permeability soil such as compacted clay liner (CCL), or a synthetic membrane liner (e.g. HDPE), or a combination both.

A capillary barrier is important to protect the integrity of an infiltration barrier (especially if a clay liner is used) and to prevent an upward movement of contaminated pore water from reaching vegetation zone.

Where compacted clay liner (CCL) is used as an infiltration barrier, excessive drying could cause the CCL to desiccate, crack and increase its hydraulic conductivity. A capillary or suction barrier is therefore provided between the CCL and the overlying soils. For some capping systems the capillary barrier may be sand or gravel to also act as a drainage layer. 


\section{CONCLUSIONS}

The hydrogeology of the residue mass in BRDA 1 is highly complicated and is strongly influenced by the dense crack network. Layers of varying hydraulic conductivities resulting from the residue deposition/filling cycles over the years also have a major influence.

Although overburden pressure causes the residue to consolidate with time, conventional theories of consolidation alone cannot be used to derive hydraulic parameters that directly affect the hydrogeology of the residue mass. Matric suction pressures due to summer drying have a major influence on the residue strength and hydraulic parameters.

The geometric mean of the hydraulic conductivity of the entire residue mass was estimated to be in the order of $1 \times 10^{-8} \mathrm{~m} / \mathrm{s}$. This was also found to be in the same order as hydraulic conductivity back calculated from measurements of underdrainage flows in BRDA 4.

Due to layering, the water levels piezometers at different depths are influenced by different systems. A low permeability layer appears to occur around $9 \mathrm{~m}$ and $10 \mathrm{~m}$ depth, forming an aquitard at the base of the upper zone. The water levels in piezometers located in the upper $6 \mathrm{~m}$ of residue are influenced by a perched water system while those piezometers below $10 \mathrm{~m}$ deep are located in the main residue water system.

The ponds that form on the residue surface during winter represent a perched water system while the true water table within the entire residue mass appears to be always below the residue surface.

Numerical simulations predicted that the ground water table within the residue mass in BRDA 1 will drop progressively from about $8 \mathrm{~m}$ to about $30 \mathrm{~m}$ depth within a period of about 30 years.

A cover system should include a low permeability barrier layer that will minimise infiltration of surface water (recharge) into the residue. The barrier layer should be designed to have a hydraulic conductivity less than $2 \times 10^{-9} \mathrm{~m} / \mathrm{s}$ to ensure that the water table will continue to fall.

The cover should also include a capillary break to limit potential for capillary rise of liquor upwards into the vegetation zone of the cover system and to control drying if a clay liner is used. 